\section{Feeding Times of British Birds}

The Rev. John Lees has recently made observations into the winter feeding hours of robins, blackbirds and blue-tits (British Birds, 41, No. 3 ; March 1948). These were made during the periods October 1945-March 1946 and October 1946-March 1947, and showed that there was a rough similarity between the feeding frequency of all three species. Each shows almost equal maxima in the forenoon and afternoon and a midday slackening of activity. Beyond this the differences are strongly marked. The robin has its maxima well separated, these being associated with the hours after sunrise and before sunset; the less active period over midday extends to about five hours. The blackbird has maxima close together, one and a half hours on each side of midday, the noon break being short and not pronounced. With the blue-tit the maxima are between those of the other two species and there is a well-defined break at midday.

\section{British Bryological Society}

THE members of the British Bryological Society assembled at Buxton during March 30-April 6 for the annual general meeting and week of field excursions. In spite of somewhat varied weather conditions, the members, under the leadership of Messrs. R. H. Hall and F. A. Sowter, visited Kinder Scout, Lathkill Dale, Dovedale and Monks Dale, and a considerable amount of field-work was accomplished. Two visits were made to Kinder Scout; on the first occasion the party proceeded to the edge of Kinder plateau via Grinds Brook, and on the second visit the ascent was made by Ashop Clough. The results of the field-work will be published later in the Trans. actions of the Society. The annual general meeting was held on April 2, with the president, Mr. A. Thompson, in the chair; the secretary, Mr. E. C. Wallace, reported a considerable increase in the number of new members. Dr. W. Watson (Taunton) and Mr. W. R. Sherrin (South London Botanical Institute) were unanimously elected honorary members in recognition of their long and valuable services to bryology and bryologists.

\section{Matter-Radiation Cycle}

REFrRRING to his communication entitled "The Matter-Radiation Cycle in the Cosmos (and the Second 'Law') : the Sun's Equilibrium" in Nature of December 27, 1947, p. 906, Mr. Alfred Lauck Parson writes: "The expression used for the temperature which could be reached by inter-stellar matter in imagined finite groups of nebulæ should have been

$$
T_{2}=T_{1} \times \sqrt[4]{\left.\frac{A_{1}(1-F)}{A_{2}\left\{F+\frac{1}{A_{2}}, 1-F\right)}\right\}}
$$

and not $T_{2}=T_{1} \times \sqrt[4]{(1-F)}, T_{1}, T_{2}$ being the temperatures of the stars and of the interstellar matter, $A_{1}, A_{2}$ their superficial areas, and $F$ the fraction of radiation $\epsilon$ scaping at the assumed radius of the group. The change does not affect the general conclusion."

\section{Colonial Service Appointments}

THe following appointments have been made in the Colonial Service: H. W. Hamlin, assistant conservator of forests, Tanganyika; H. S. H. Watson, assistant conservator of forests, Northerm Rhodesia, J. R. Fletcher, inspector of mines, Malaya; A. J. MacNair, temporary agricultural (cocoa survey) officer, Gold Coast; J. Phipps, entomological biologist, Tanganyika; T. C. Stibbs, mining inspector, Lands and Mines Department, British Guiana; G. W. Lock (senior agricultural officer, Tanganyika), senior research officer, Tanganyika; A. E. S. McIntosh (senior agricultural officer, Federation of Malaya), deputy director of agriculture, Federation of Malaya; F. J. Pound (senior agricultural officer, Trinidad), deputy director of agri. culture (crop husbandry), Trinidad; G. M. Roddan (deputy agricultural adviser, Colonial Office), deputy director of agriculture, Kenya; O. S. Swainson (senior agricultural officer, Zanzibar), director of agriculture, Zanzibar; S. G. Willimott (chemist, Department of Chemistry, Federation of Malaya and Singapore), chemist (soils), Federation of Malaya; H. A. Hay-Barclay (senior veterinary officer, Nigeria), regional assistant director of veterinary services, Nigeria; A. Fulton (senior veterinary officer, Gold Coast), director of veterinary services, Sierra Leone/Gambia ; L. R. Hutson (chief veterinary officer, Leeward Islands), veterinary officer, Department of Science and Agriculture, Barbados; J. W. Macaulay (veterinary research officer, Northern Rhodesia), senior veterinary research officer, Northern Rhodesia; J. Morton (veterinary officer, Nigeria), regional assistant director of veterinary services, Nigeria; H. G. Stewart (veterinary officer, Uganda), senior veterinary officer, Uganda.

\section{Announcements}

Prof. Paul Fallot, professor of geology in the University of Nancy, has been elected a member of the Section of Mineralogy of the Paris Academy of Sciences, in succession to the late Léon Bertrand.

THE Stephen Paget Memorial Lecture of the Research Defence Society will be delivered by Prof. P. A. Buxton on the occasion of the annual general meeting of the Society, to be held at the Royal Society of Tropical Medicine, London, on June 8. Prof. Buxton's address will be on "Tsetse Flies and the Development of Africa", and it will be illustrated by a film in colour.

JoHN A. HARrison, assistant education officer of Surrey County Council, has been appointed director of the Educational Foundation for Visual Aids. Mr. Harrison has had considerable experience of the use of visual aids to education both in the Services and in civilian teaching. During 1931-45 he used visual aids almost.continuously in all types of education; in 1938, while holding a Carnegie research scholarship, he visited many American schools, giving particular attention to the use of visual aids.

AN appointment is to be made shortly to the Dewar Research Fellowship, tenable in the Davy Faraday Research Laboratory of the Royal Institution. The Fellowship, which is of the value of $£ 1,000$ a year, is open to persons of either sex, and is for a period of three years. The subject of research must be related to the chemical or physical sciences. Previous holders have been Prof. A. R. Ubbelohde, of the Queen's University, Belfast, and Dr. Kathleen Lonsdale, of University College, London. Applica. tions must be made by letter to the General Secretary, Royal Institution, 21 Albemarle Street, London, W.1, before June 30 . 